\title{
LOS CONCEPTOS DE APROPIACIÓN Y PODER EN LA TEORÍA ECONÓMICA DE MAX WEBER
}

\author{
Esteban Torres Castaños*
}

Fecha de recepción: 26 de octubre de 2010. Fecha de aceptación: 16 de febrero de 2011.

\begin{abstract}
RESUMEN
Ofrecemos al lector una primera investigación sobre el concepto de apropiación de Max Weber, en particular sobre la relación que éste establece con la noción de poder. A partir de ello, en una instancia de mayor concreción, nos concentramos en la forma en que dicho vínculo determina el pensamiento económico del autor. Si bien se reconoce la centralidad del primer concepto para la edificación de su sociología económica, no registramos antecedentes de trabajo sobre la categoría. Entre otros aspectos, la investigación descubre algunos elementos que permiten poner en cuestión la relación establecida entre las expresiones instituida e instituyente del concepto de apropiación. Con el siguiente trabajo pretendemos contribuir a la comprensión, la crítica y el uso renovado de la teoría económica y social de Max Weber en America Latina.
\end{abstract}

Palabras clave: Max Weber, Teoría económica, Poder, Apropiación, Desarrollo.

\section{THE CONCEPTS OF APPROPRIATION AND POWER IN THE ECONOMIC THEORY OF MAX WEBER}

\begin{abstract}
We provide the reader with an initial study of Max Weber's concept of appropriation, focusing in particular on the relationship he establishes between it and the notion of power. Based on this link, and using a more concrete example, we concentrate on the way it determines the author's economic thinking. While the importance of the first concept in the building of his economic sociology is recognized, we do not look at previous references for this category. Among other things, the study discovers some elements that enable us to question the relationship established between the instituted and instituting expressions of the concept of appropriation. With this study we intend to contribute to the understanding, criticism and renewed use of Max Weber's economic and social theory in Latin America.
\end{abstract}

Key words: Max Weber, economic theory, Power, Appropriation, Development.

* Investigador del Centro de Estudios Avanzados, Universidad Nacional de Córdoba, República Argentina. Becario Tipo ir de conicet. Correo electrónico: esteban.tc@conicet.gov.ar 


\section{LES CONCEPTS D'APPROPRIATION ET DE POUVOIR DANS LA THÉORIE ÉCONOMIQUE DE MAX WEBER}

\section{Résumé}

Nous offrons au lecteur une première recherche sur le concept d'appropriation de Max Weber, notamment sur la relation que celui-ci établit avec la notion de pouvoir. A partir de là, dans un souci de concrétisation, nous nous centrons sur la façon dont le lien mentionné détermine la pensée économique de cet auteur. Bien que soit reconnu le caractère central du premier de ces concepts pour l'édification de sa sociologie économique, nous n'avons pas répertorié de précédents travaux sur la question. Entre autres aspects, la recherche dévoile des éléments qui autorisent à mettre en question la relation établie entre l'expression instituée du concept d'appropriation et celle qui institue. Avec ce travail, nous prétendons contribuer à la compréhension, la critique et l'usage rénové de la théorie économique et sociale de Max Weber en Amérique latine.

Mots clés : Max Weber, théorie économique, pouvoir, appropriation, développement.

\section{OS CONCEITOS DE APROPRIAÇÁO E PODER NA TEORIA ECONÔMICA DE MAX WEBER}

\section{Resumo}

Oferecemos ao leitor uma primeira pesquisa sobre o conceito de apropriação de Max Weber, em particular sobre a relação que esta estabelece com a noção de poder. A partir disto, numa instancia de maior concretude, nos concentramos na forma na qual dito vinculo determina o pensamento econômico do autor. Se bem se reconhece a centralidade do primeiro conceito para a edificação da sua sociologia econômica, não registramos antecedentes de trabalho sobre a categoria. Entre outros aspectos, a pesquisa descobre alguns elementos que permitem colocar em questáo a relação estabelecida entre as expressóes instituida e constituinte do concepto de apropriação. Com o seguinte trabalho pretendemos contribuir à compreensão critica e o uso renovado da teoria econômica e social de Max Weber na America Latina.

Palavras-chave: Max Weber, Teoria econômica, Poder, Apropriaçáo e Desenvolvimento.

马克斯・韦伯经济理论中的 “占有” 及 “权力” 概念 埃斯特凡・托雷斯・卡斯塔尼奥斯

概要

我们为读者提供有关马克斯 - 韦伯的 “占有” 概念的第一手研究资料，尤 其是他建立的其与 “权力” 概念的相互关系。从这里出发, 在更加凝练的 要求下，我们专注于这种关系决定作者的 “经济思维”的方式。尽管对于 组成他的经济社会学的第一个概念的中心点我们已有了认识, 我们并没有 此范畴内前期工作的记录。在其他方面, 我们的研究发现了能够质疑建立 占有概念与它所建立的表述之间关系的成分。在接下来的研究中, 我们尝 试对马克斯 - 韦伯的经济及社会学理论的理解、批评和现实应用做一点贡 献。

关键词：马克斯-韦伯, 占有, 权力, 发展 


\section{APUNTES PRELIMINARES}

Para el siguiente trabajo empleamos como fuente bibliográfica aquellos textos de Weber donde registramos tanto el desarrollo como el uso de los conceptos de apropiación y de poder. Ello impone ciertas limitaciones de partida que el lector imagina. En la construcción del discurso analítico apelamos con frecuencia y de forma inevitable a la generalización, lo que en la práctica implica la equiparación de la selección de textos con la totalidad del pensamiento escrito del autor.

Señalamos que en principio no hay antecedentes de una aproximación por el estilo a la obra del sociólogo alemán. Si bien en algunos casos se reconoce la centralidad del concepto de apropiación para la edificación de su sociología económica y su perspectiva sociológica general (Swedberg, 1999: 262; Poggi, 1988: 82), resulta curioso que no haya llamado la atención de gran parte de sus comentaristas, incluso de los más importantes (ver Bendix, 1979; De Feo, 1972; Gerts y Wright Mills, 1946; Giddens, 1972; Gil, 1978; Massot, 1986; Mommsen, 1974; Moreno Blauchemin, 1988; Nisbet, 1966; Robert y Gassman, 1985; etcétera). Una exploración preliminar del concepto de apropiación de Weber nos deja por lo tanto en relativo desamparo frente a sus obras, privándonos en la práctica de fuentes bibliográficas secundarias, que por lo general, salvo honradas excepciones, se hacen presentes en nuestro trabajo para ilustrar aspectos de carácter secundario. Esta constatación redobla nuestro interés por la investigación a la vez que limita en buena medida la extensión y la profundidad del campo de debate y de problematización teórica del trabajo.

Luego de ofrecer una caracterización general del concepto, nos concentramos en la reconstrucción y el análisis de las relaciones que propone el autor entre la apropiación y el poder, y entre la apropiación y la economía, dejando para un próximo trabajo la relación entre la apropiación y el plexo de actores sociales, la política, la cultura y finalmente la técnica, lo que finalmente nos permitiría asumir una visión de conjunto, más apegada a la "literalidad" de Weber, así como a su método de indagación multidimensional.

\section{LA APROPIACIÓN: ASPECTOS GENERALES}

Proponemos un punto de partida obvio pero necesario. Como toda categoría central de Weber, la idea de apropiación no tiene en apariencia un valor normativo determinado, sino que se inscribe en el marco de su "irracionalismo ético", que algunos comentaristas eligen contraponer a la axiología de Hegel y Marx. En su acepción dominante, Weber define el concepto de apropiación en 
relación a cierta noción sociológica de probabilidad, vinculada a dos conceptos fundamentales como son los de derecho y propiedad. El autor define el derecho en un sentido socioeconómico, como una "probabilidad apropiada" y la propiedad como "probabilidad hereditariamente apropiada"1 (1922: 36). Resulta llamativo constatar las pocas líneas que emplea Weber para definir el concepto de apropiación. La única definición explícita aparece de forma suscinta en las primeras páginas de su Historia económica general. Allí se la define como "ordenamiento y forma de la propiedad" (1923: 15). Para el autor, lo apropiado sería allí lo que es objeto del ordenamiento de la propiedad (1923: 14). Hace referencia a la propiedad en un sentido económico, más abarcativo que la acepción jurídica habitual. Hasta aquí el concepto de apropiación expresa lo instituido, lo "ya-apropiado", principalmente en el ámbito económico. Se encuentra muy próximo a la idea de posesión, ${ }^{2}$ y se asocia directa o indirectamente a cierta noción de "protección jurídica” (1922: 36).

La apropiación involucra en la teoría de Weber una multiplicidad de "objetos". La variedad y la naturaleza de los mismos permiten fijar una primerísima impresión sobre el alcance y las formas que adquiere el concepto. Los objetos principales de apropiación que selecciona el autor se despliegan en los diferentes ámbitos de su teoría social, aunque en mayor medida en la economía y la política. A modo de anticipación, podemos indicar que en el plano político o de la dirección estatal, Weber hace referencia en mayor medida a la apropiación de los poderes de mando y de los medios administrativos (materiales), empleando también otras nociones como la apropiación de cargos, de poderes políticos, de poderes de administración, de poder representativo, etcétera. En el plano económico, los objetos centrales de apropiación son las oportunidades de trabajo, los medios materiales de producción y los puestos directivos. Pero el concepto de apropiación propone otras variaciones. Como señala Weber, "hay apropiación

1 La definición textual de Weber es la siguiente: "Se llama propiedad al conjunto de probabilidades hereditariamente apropiadas por un individuo o una comunidad o una sociedad; siendo propiedad libre en el caso en que ésta sea enajenable (1922: 36).

2 En muchas ocasiones “apropiación” y “posesión” aparecen prácticamente como sinónimos. Weber habla indistintamente de posesión o apropiación de poder, de poderes de disposición, del suelo o de la tierra, de bienes, de la riqueza, de doctrinas, etcétera, pero también hace referencia, entre otras, a la "posesión apropiada" (1922: 495, 496), lo cual sugiere un sentido de la apropiación más próxima a cierta idea de acción que luego precisaremos. Mientras que la posesión hace referencia a lo apropiado o lo ya-apropiado, no sucede siempre lo mismo con la apropiación, en la medida que en algunos casos hace referencia a cierta idea de acción, completando una idea de apropiación como proceso. 
en todos sus grados y cualidades" (1922: 39). Si bien en ningún momento sistematiza los grados de apropiación, distingue en el uso entre apropiaciones plenas, parciales y apropiaciones nulas o inexistentes.

Advertimos que Weber emplea tanto el concepto de apropiación como el de expropiación, y si bien no lo explicita, entiende a cualquiera de ellos en una relación irreductible y no dialéctica con su contrario. De esta forma concibe la idea de apropiación o de expropiación como una relación apropiación-expropiación. Constatamos que usa el concepto de apropiación en mayor medida que el de expropiación, pero ello no implica que le otorgue mayor relevancia. Muchas veces incluso ocurre lo contrario. A modo de ejemplo, el autor decide señalar que es el proceso de expropiación (y no el de apropiación) el que permite el avance progresivo de la orientación racional de la actividad humana, tesis central de su teoría general. Para el sociólogo alemán, los procesos de expropiación política y económica fueron en algún sentido los factores precipitantes de la modernidad, en tanto permitieron el desarrollo del Estado moderno y de la empresa capitalista. ${ }^{3}$ La profesionalización de la política, la aparición de las primeras categorías de "políticos profesionales", sería igualmente para Weber un producto del proceso de expropiación política (1959: 92). Cualquiera sea el caso, el movimiento apropiación-expropiación se puede reconocer como un aspecto dinámico central en su obra.

Muy a grandes rasgos, podemos identificar tres niveles de abstracción en los que "opera" el concepto de apropiación, aunque éstos se desdibujan permanentemente. Podríamos seńalar que en un primer momento, Weber conceptualiza la apropiación al mismo nivel e indirectamente relacionada con la noción de poder (o probabilidad-poder); en una segunda instancia, adquiriendo mayor concreción, se vincula directamente -aunque en un sentido amplio- con la idea de dominación (o probabilidad-dominación), y finalmente, en el nivel más concreto, la noción de apropiación se introduce en los diferentes ámbitos de lo social (económico, político, social), transformándose en conceptos específicos. De este modo, a diferencia de Marx, la idea de apropiación o expropiación le permite ir más allá de lo económico, para caracterizar las diferentes esferas de la acción

3 Dice Weber: "En todas partes el desarrollo del Estado moderno comienza cuando el príncipe inicia la expropiación de los titulares "privados" de poder administrativo que junto a él existen: los propietarios en nombre propio de medios de administración y de guerra, de recursos financieros y de bienes de cualquier género políticamente utilizables. Este proceso ofrece analogía total con el desarrollo de la empresa capitalista mediante la paulatina expropiación de todos los productores independientes" (1959: 91). 
social, en particular la esfera política. ${ }^{4} \mathrm{Si}$ bien no existe por parte de los actores de la apropiación (ni siquiera de las clases sociales) una tendencia exclusiva o siquiera constante a partir de intereses puramente económicos (1922: 695), señalamos aquí y veremos más adelante que en semejanza con Marx la idea de apropiación de Weber se desarrolla principalmente en relación al pensamiento económico.

Estos y otros elementos que presentaremos nos permiten suponer que el uso complejo y multidimensional que hace el autor de la idea de apropiación desborda en varios sentidos la definición dada al comienzo. Constatamos que el concepto no se agota en la dimensión de lo ya-apropiado o de las probabilidades apropiadas. Lo que aquí señalamos, en cierta manera adopta la forma de un discurso hipotético que subyace a la investigación. Supondremos que la apropiación es a la vez acción y estructura, o más específicamente acto y estructura de probabilidad o posibilidad.

Ahora bien, es posible que llegado a este punto el lector aún no tenga claro o siquiera insinuado cuál es el sentido y la relevancia de investigar el concepto de apropiación de Weber. Siendo que no es necesario legitimar al autor, ¿qué hay de especial en esta idea que la haga merecedora de estudio? Sin ánimo de profundizar en ello, aquí ofrecemos algunos supuestos generales:

a) El concepto de apropiación resulta crítico para comprender la teoría social de Weber y en particular su idea de poder, de dominación y de cambio social. La relación apropiación-expropiación ofrece una forma general de interpretar el proceso de avance-y-retroceso continuo de los intereses y de las probabilidades de poder y dominación entre actores (clases, estamentos, partidos e individuos).

b) A diferencia de lo que muchos comentaristas sugieren (entre ellos Mommsen, 1974), consideramos que es el devenir o la transformación del proceso de apropiación antes que la omnipotencia de las estructuras burocráticas, lo que explica en última instancia para Weber las causas de la "enajenación" del hombre, tanto en el mundo del trabajo como en la sociedad política. Por lo tanto, si bien acordamos con Nisbet cuando señala que para Weber la burocratización es una poderosa manifestación del principio histórico de la

4 Como señala Giddens, "Weber rechaza la concepción de que la expropiación del trabajador de sus medios de producción se ha limitado únicamente a la esfera económica; cualquier modalidad organizativa dotada de una jerarquía de autoridad puede verse sometida a un proceso de expropiación. En el Estado moderno, "el funcionario experto, basado en la división del trabajo, se ve totalmente expropiado de la posesión de sus medios de administración” (1976[1972]: 54). 
racionalización (Nisbet, 1966: 195), consideramos que la idea de apropiación o expropiación es al menos un principio igualmente fundamental para explicar dicho proceso. Sugerimos que es en especial a partir de la idea de apropiación que Weber se ocupaba a su manera del mismo tema que Karl Marx y Friedrich Nietzsche, es decir, de la "enajenación" del hombre en las envolturas de las estructuras sociales y económicas creadas por el mismo.

c) Finalmente sugerimos que a partir de su relación con la idea de lucha, Weber extiende el concepto de apropiación desde el ámbito de la sociología al de la historia general y la historia de la cultura. La historia, que Marx representa habitualmente como historia de la lucha de clases, se presenta ocasionalmente en Weber como lucha por la apropiación o expropiación recíproca entre actores (1922: 212). ${ }^{5}$

\section{APROPIACIÓN Y PODER}

Pese a su estrecha interdependencia conceptual, la relación entre apropiación y poder no se desarrolla explícitamente en la obra de Weber. Si bien al leer detenidamente sus textos es posible intuir e incluso reconocer el vínculo y las semejanzas que los unen, resulta difícil identificar sus diferencias y por lo tanto sus modos de complementación al interior de la teoría, y ello quizás porque ambos se definen en primera instancia en relación al concepto de probabilidad o posibilidad (que el autor emplea como sinónimos). Para Weber, todo poder es probabilidad: "poder significa la probabilidad de imponer la propia voluntad, dentro de una relación social, aun contra toda resistencia y cualquiera que sea el fundamento de esa probabilidad" (1922: 43, 669). En la forma de "derecho" o de "propiedad", toda apropiación es probabilidad o posibilidad apropiada. Siendo que el poder es probabilidad, toda apropiación es poder apropiado. En todos los casos, la apropiación fija una relación de antecedente con el poder. Ahora bien, como veremos más adelante, para establecer las diferencias

5 Dice Weber: "Finalmente, la realidad histórica es también y muy en particular una lucha constante, latente las más de las veces, entre el señor y el cuadro administrativo por la apropiación o expropiación recíprocas. Decisivo para casi toda la evolución cultural fue:

1. El resultado de esta lucha como tal.

2. El carácter de aquella capa de los funcionarios de él dependientes que ayudaron al soberano a ganar su lucha contra los poderes feudales u otros poderes apropiados (...)" (1922: 212). 
sustanciales entre apropiación y poder es preciso avanzar sobre su teoría de la dominación y su teoría económica, particularmente su idea de libre mercado, y de allí retornar a las abstracciones del poder general, sin cerrarse a los conceptos específicos de poder que el autor va proponiendo. Es necesario recordar que para Weber la dominación es una forma de poder (1922: 695), un caso especial y concreto de poder. En el sentido general de poder, y, por tanto, de posibilidad de imponer la propia voluntad sobre la conducta ajena, la dominación puede presentarse en las formas más diversas ${ }^{6}$ (1922: 696). Dado que la diferencia entre poder y dominación en Weber es principalmente de nivel de abstracción, la segunda se define igualmente a partir de la idea de probabilidad. Weber entiende la dominación como "la probabilidad de encontrar obediencia a un mandato de determinado contenido entre personas dadas (...)" (1922: 43, 669). Las relaciones de poder y de dominación están sujetas y en conflicto con las relaciones de apropiación presentes y futuras.

Si bien para el autor el poder precede toda apropiación, ${ }^{7}$ no todo poder procede o se basa en la apropiación, ni puede ser apropiado. Excluyendo la idea temprana y ciertamente marginal de "apropiación subjetiva" que tan sólo menciona Weber en La ética protestante y el espíritu del capitalismo (y que retomaremos más adelante en el apartado de "Apropiación y cultura"), diríamos que la primera diferencia esencial entre apropiación y poder (y por consiguiente también respecto a la dominación) es el carácter exclusivamente material del primer concepto. La apropiación es un proceso en y con los materiales y sus formas, mientras que el poder incluye eventualmente una dimensión simbólica o inmaterial, cuya referencia es la idea de reconocimiento. Ello queda evidenciado en la descripción que realiza el autor de la dominación de tipo carismática, identificada con el ámbito de la política. A diferencia del tipo puro de dominación tradicional, y eventualmente de la dominación de tipo racional o legal con administración burocrática, en la dominación carismática -hasta tanto ésta no se rutinice- no existe apropiación de los poderes de mando ni de los medios de

6 Entre las numerosas formas posibles, Weber distingue dos tipos radicalmente opuestos de dominación. Por una parte, la dominación mediante una constelación de intereses (especialmente mediante situaciones de monopolio); por otra, mediante la autoridad (poder de mando y deber de obediencia) (1922: 696).

7 Como ejemplo de ello, dice Weber: “(...) esta situación es un desarrollo de la división estamental de poderes y precede de la apropiación por privilegiados de los poderes de mando y de los medios administrativos, y también de necesidades fiscales (...) determinadas por exigencias económico-sociales crecientes (...), pero no absolutamente (1922: 227). 
administración (1922: 125). El poder sobrenatural, divino y superior a toda cotidianeidad, con el que Weber describe al carisma del héroe (1922: 880) se funda en el reconocimiento y no en la apropiación, y requiere de la corroboración permanente por parte de los "dominados carismáticos" (1922: 193). La fuerza de la confianza, de las variaciones de la conciencia, de las nuevas actitudes de los "adeptos" frente a la revelación de las cualidades carismáticas, opera al margen de las relaciones de apropiación. Es recién a partir o en el caso de la cotidianización del carisma donde vuelve a suceder la apropiación estamental y/o tradicional de poderes de mando (1922: 202). Ello se instaura muy a menudo al momento de designación del sucesor del jefe carismático, siguiendo una tendencia al afianzamiento, es decir, a la legitimación de las posiciones de mando y de probabilidad económica (1922: 202). De esta forma se realiza lo que Weber denomina la apropiación carismático-hereditaria de probabilidades (1922: 204). Por lo tanto, podríamos sugerir que la apropiación es el acto y el sustrato material crítico del poder. Dicho de otra manera, podría ser la condición material generalizada de la probabilidad, si bien no excluyente, como veremos a continuación.

Una segunda diferencia entre poder y apropiación involucra para Weber la forma de administración típicamente moderna, vinculada a la dominación legal con administración burocrática. La apropiación queda excluida del poder racional puro, que estructura la dominación a partir de la imposición de un ordenamiento impersonal. Los poderes de gobierno pueden ser $a$ ) apropiados o bien, $b$ ) atribuidos por características del cargo (1922: 39). En este segundo caso, como es de saber común, el fundamento primario de la legitimidad descansa en la creencia en la legalidad de ordenaciones estatuidas y de los derechos de mando de los llamados por esas ordenaciones a ejercer la autoridad (autoridad legal). De esta forma, Weber entiende que en el caso más racional no existe apropiación de los cargos por quien los ejerce (1922: 39). Señala que "donde se da un 'derecho al cargo' (como, por ejemplo, entre los jueces y actualmente en partes crecientes de la burocracia y el proletariado) no sirve generalmente a un fin de apropiación por parte del funcionario, sino de aseguramiento del carácter puramente objetivo ('independiente'), sólo sujeto a normas, de su trabajo en el cargo" (1922: 39). Vemos cómo en el caso racional rige el principio de la separación plena entre el cuadro administrativo y los medios de administración y producción.

Una tercera diferencia entre poder y apropiación se registra en el pensamiento económico de Weber, en relación con la naturaleza contractual del trabajo. Para caracterizar al mercado de trabajo capitalista Weber aplica una contraposición formal entre apropiación y libertad (veremos en "Apropiación 
y economía” que ello tiene sus complicaciones), suscitando a partir de ello una nueva distinción entre apropiación y poder. A diferencia del trabajo servil o esclavo (donde hay apropiación de la persona del obrero por el propietario del puesto de trabajo) y de la apropiación de los puestos de trabajo por los obreros (1923: 15), la contratación en el mercado estaría libre de apropiación. En la teoría de Weber sobre la economía capitalista, las relaciones económicas se dividen en relaciones de apropiación -técnicas y de explotación-y relaciones de mercado (1922: 117). En las relaciones de libre mercado hay ausencia de apropiación de puestos de trabajo (no así, claro está, respecto a los medios materiales de producción y a los cargos directivos). Para Weber, el trabajo libre implica que existan personas, no solamente en el aspecto jurídico sino en el económico, obligadas a vender libremente su actividad en el mercado (1923: 238). Señala a su vez que el trabajo libre, así como la apropiación de todos los bienes materiales de producción (junto a la técnica racional, el derecho racional y la comercialización de la economía) se constituyen en premisas de existencia de las grandes empresas en el capitalismo moderno (1923: 238). Weber advierte que la libertad del trabajador en los términos mencionados hace imposible su apropiación, sin aclarar que ello corre para el propietario de los medios de producción, pero no necesariamente para el propio trabajador respecto a sí mismo, ya que puede adquirir poder de disposición sobre su propia fuerza de trabajo en la medida en que puede contar con su uso por propia voluntad sin impedimentos de terceros (cualquiera sea el fundamento de esa probabilidad: orden jurídico, convención, costumbre o fijación de intereses, 1922: 53).

Otra diferencia relevante entre apropiación y poder, tiene que ver con la relación que éstos establecen con los procesos o criterios de valorización social que propone Weber, y en este sentido se relaciona con la primera diferencia señalada. Dejando de lado los aspectos que atañen a su irracionalismo y pluralismo axiológico, diremos que a diferencia del poder, el concepto de apropiación en todas sus formas permanece al margen de las operaciones de significación, o quizás mejor dicho, de los "efectos de significación" que propone el autor en la teoría. La valoración, que tanto en Nietzsche como en Weber es la condición constitutiva de la representación del mundo, en cierta forma se involucra en la teoría social de Weber con el concepto de poder y no así con el de apropiación. Si bien en la obra de éste ambos conceptos son relacionales y eventualmente podrían caracterizarse a partir de representaciones dialógicas o dialécticas, prácticamente sólo el concepto de poder puede adquirir un valor "psicosocial". En Weber, todo poder puede eventualmente constituirse en la base de una pretensión específica de prestigio (1922: 669). Por otro lado, si 
bien el autor admite que no todo poder produce honor social -como es el caso del poder "meramente económico"- en términos generales reconoce al poder como base de dicha investidura (1922: 195). ${ }^{8}$ Invirtiendo los términos, podríamos decir que el honor y el prestigio hacen posible en Weber la expansión del poder: "El puro prestigio del poder significa prácticamente, en cuanto 'honor del poder', el honor de disponer del mismo sobre otras estructuras políticas, la expansión del poder, bien que no siempre en la forma de la asimilación o de la sumisión (1922: 669)".?

Poder y apropiación difieren también en Weber según el vínculo que establecen con los instintos y las emociones. A diferencia de la apropiación, la idea de poder se registra como elemento de cultura a nivel instintivo y emocional. Ello se constata cuando reconoce en los políticos cierto "instinto de poder" (1959: $153,155),{ }^{10}$ un sentimiento de poder fuera de lo cotidiano, que según el autor es producto de la conciencia de tener una influencia sobre los hombres, de participar en el poder sobre ellos y, sobre todo, el sentimiento de manejar los hilos de acontecimientos históricos importantes (1959: 153). En el mismo texto Weber reconoce que el ansia de poder es una de las fuerzas que impulsan la política (1959: 156), pero en ningún momento ésta deviene y proviene de una suerte de ansia de apropiación, lo cual es curioso, siendo que para el autor la apropiación es inherente a la huella material de lo personal, que se contrapone al orden impersonal de la técnica y la racionalidad pura. Una excepción incómoda en este sentido es la idea de "intereses de apropiación", que Weber menciona en

8 Sobre la relación entre poder económico y poder general, Weber manifiesta que: "Como es natural, el poder 'condicionado económicamente' no se identifica con el 'poder' en general. Más bien ocurre lo inverso: el origen del poder económico puede ser la consecuencia de un poder ya existente por otros motivos. Por su parte, el poder no es ambicionado sólo para fines de enriquecimiento económico" (1922: 683).

9 Las razones generales de la "dinámica del poder", con la que Weber fundamenta el carácter expansionista de las comunidades políticas (exclusivamente), más específicamente de las "grandes potencias" (1922: 670) son en cierta forma extrapolables en su teoría al conjunto de los actores sociales, incluyendo al individuo. Con este rasgo expansionista Weber alude a la búsqueda de ampliación del ámbito abarcado por la propia comunidad política mediante el uso de la fuerza (1922: 670).

10 "Sólo una línea delgadísima separa en este punto a Max Weber de la concepción de Nietzsche en el sentido de que la 'voluntad de poder' es la ley fundamental y el resorte de toda cultura y que los grandes individuos se distinguen de las masas precisamente en que consecuentemente y sin ilusiones aceptan esta ley y la convierten en criterio de su actuar" (Mommsen, 1974: 152). 
la caracterización de ciertas teorías económicas socialistas y/o estatistas pero que en ningún momento desarrolla. ${ }^{11}$

Hasta aquí hemos señalado diferencias entre la noción de apropiación y el concepto general de poder de Weber. Ahora bien, si en vez de ello comparásemos aquélla con la categoría económica de poder de disposición o poder dispositivo, deberíamos invalidar en gran medida las diferencias señaladas, y retrotraer el análisis a los atributos comunes a ambos conceptos, que esbozamos a comienzos de este punto. Hablamos de poder dispositivo como poder de disposición efectivo de personas, bienes y servicios económicos (1922: 632). A diferencia del poder en general, todo poder de disposición es material y formal, procede o se basa en la apropiación, y ha sido previamente apropiado. Dicho de otra forma, todo poder de disposición es poder apropiado. En todo momento, los actores se encuentran "en posesión de un poder de disposición (...)" (1922: 532). Veremos en el próximo punto cómo el concepto de apropiación de Weber antecede en todos los casos a la probabilidad económica.

\section{APROPIACIÓN, PODER Y ECONOMÍA}

$\mathrm{Al}$ igual que la política, aunque no en el mismo nivel de determinación, la economía o el orden económico es para Weber una dimensión parcial del proceso social de racionalización, así como del proceso general de poder. Dicho sentido del límite acuerda con la visión de Giddens -que corresponde a la del saber común de las ciencias sociales contemporáneas- cuando sugiere que la relación de clase entre capital y trabajo no expresa para Weber el carácter esencial del capitalismo (Giddens, 1972: 56). Weber llama "orden económico" a lo económico como un todo, y lo define como "la distribución de poder de disposición efectivo sobre bienes y servicios económicos que se produce consensualmente-consensos- según el modo de equilibrio de los intereses, y a la manera como esos bienes y servicios se emplean según el sentido de ese poder fáctico de disposición que descansa sobre el consenso" (1922: 251). Esta distribución de poderes de disposición ocurre entre trabajadores (individuales o asociaciones),

11 En la presentación de las categorías centrales de análisis de la economía de cambio y la economía planeada, Weber hace referencia al socialismo "de consejo de fábrica" y a los intereses de apropiación de los trabajadores (1922: 86). Luego más adelante, al aludir al problema de la distribución en las concepciones económicas “comunistas", Weber plantea una relación positiva entre una economía planificada racional y el desarrollo de los intereses de apropiación (1922: 86). 
propietarios (individuales o asociaciones) y asociación de terceros de carácter regulador. Nuestro autor señala que el proceso de socialización de la economía de cambio presupone, por una parte, la apropiación de los soportes materiales de las utilidades y, por otra, la libertad de mercado (1922: 87). Pero pese a distinguir entre ambos tipos de relaciones, y de sostener que "la casuística de las relaciones de apropiación -técnicas y de explotación-y de mercado es enormemente variada" (1922: 117), en cierta forma sugiere que el orden económico prácticamente es determinado por el modo de apropiación, a partir de los poderes de disposición, esto es, en función de los poderes de los poseedores de "derecho" y de "propiedad" (en la acepción del autor). Las explicaciones de Weber llevan fácilmente a concluir que es a medida que éstos hacen crecer su poder de disposición sobre los soportes materiales, acompañado del avance de la libertad de contratación del trabajo que se extiende la libertad de mercado. ${ }^{12}$ En líneas generales, la economía concebida por Weber es un orden jurídico-económico de gestión, basado en las probabilidades apropiadas, esto es, en el derecho y la propiedad, pero al mismo tiempo producido por intereses individuales. Desde una idea contractual de equilibrio, señala que toda gestión económica dentro de la economía de cambio se emprende y lleva a cabo por los individuos para cubrir intereses propios, ideales o materiales (...) (1922: 167). ${ }^{13}$ Se hace patente, tal como señala Weber, "la influencia sociológica y económica del orden jurídico sobre el individuo (1922: 251).

El lector intuye sin problemas que la noción principal de poder que especifica Weber en su modelo económico es la de poder de disposición o poder dispositivo, pero lo que no resulta evidente es que ésta opera en la práctica como sinónimo de la idea de apropiación. La profusión de conceptos y acepciones similares en la teoría económica de Weber, así como su difícil lectura, en muchos casos no colabora con la distinción. El poder dispositivo es una de las ideas centrales de su pensamiento económico, si bien no ofrece una definición

12 Señala Weber: "La libertad de mercado crece en importancia 1 ) a medida que es más completa la apropiación de los soportes materiales de las utilidades, especialmente de los medios de obtención (producción y transporte). (...) Pero, además, aquella importancia crece, 2) cuanto mayor sea la limitación de la apropiación a dichos soportes de la utilidad (1922: 87)".

13 En este sentido Weber no establece diferencia entre la economía capitalista y una supuesta economía socialista: "En una economía socialista organizada no sería en principio diferente. (...) serían también entonces lo normal procesos de apropiación de toda clase y luchas de intereses (...) Pero siempre estaría este interés del individuo - eventualmente: los intereses homogéneos de muchos frente a otros intereses antagonistas- detrás de toda acción (1922: 167)". 
clara y sistemática del mismo. Weber indica que "se encuentran dentro del poder de disposición de un sujeto económico ciertas utilidades (bienes, trabajo $\mathrm{u}$ otros portadores de ellas) cuando se puede contar con su uso por propia voluntad sin impedimento de terceros, cualquiera que sea el fundamento de esa probabilidad: orden jurídico, convención, costumbre o fijación de intereses" (1922: 53). A nuestro juicio, esta afirmación, aunque incompleta y en cierta forma asistemática, es lo más preciso que ofrece el autor sobre el significado de poder de disposición. Decimos incompleta porque en el orden económico de Weber, el poder de disposición puede conllevar poder de disposición sobre el uso de cosas (productos y servicios) y utilidades, ${ }^{14}$ pero también disposición sobre la explotación de cosas y personas. Hay poder de disposición cuando el sujeto económico se ha apropiado de la probabilidad, esto es, cuando dispone de derechos y de propiedad en un sentido económico. Dejemos en claro aquí un aspecto clave: todo poder de disposición implica apropiación en la economía. La apropiación como probabilidad, o sea como poder de disposición, es por lo tanto -recuperando la rectificación hecha- "el poder contar con el uso y la explotación de cosas, utilidades y personas por propia voluntad", o lo que es lo mismo, tener o poseer (y no tanto adquirir) derechos y propiedad de uso y explotación.

En la lógica causal de Weber, "poder disponer" implica antes "tener" o "poseer" que "poder adquirir". El autor define el concepto de adquisición como una "acción orientada por las probabilidades de ganancia de nuevos poderes de disposición sobre bienes" (1922: 68), y por lo tanto en relación con cierta noción de nueva apropiación, pero luego prácticamente no lo emplea en su análisis económico. Incluso el hecho que la adquisición adopte el sentido restringido de acción lucrativa, tampoco llega a explicar su postergación. La cuestión espinosa de la adquisición de derechos y propiedad, sólo se deja leer entrelíneas en un momento, cuando sugiere que el poder dispositivo se produce en un espacio de "adquisiciones planeadas de poderes de disposición", donde surge la relación con el "derecho" (1922: 51). Decimos por lo tanto que en la acepción dominante de Weber, la apropiación es probabilidad apropiada ${ }^{15}$ y no probabilidad

14 A modo de ejemplo: "Apropiación por los trabajadores de la utilización lucrativa de los productos del trabajo (...)" (1922: 98-100).

15 Weber define el derecho como "probabilidad apropiada", pero ello no le impide hablar de apropiación de derechos, o por ejemplo, de "tener apropiado el derecho a la representación" (1922: 235). Ello da cuenta de ciertas ambigüedades que acompañan la definición del concepto de apropiación. 
de apropiar: posesión y no adquisición. Ello sin duda concuerda con que para el autor la "posesión" y la "no posesión" son efectivamente las categorías fundamentales de todas las situaciones de clase (1922: 684), ${ }^{16} \mathrm{si}$ bien luego añade que "el poder que otorga la posesión en cuanto tal, surte efecto cuando han quedado descartados en lo posible todos los demás motivos determinantes de las relaciones recíprocas" (1922: 686), pero sin mencionar a qué motivos hace referencia.

En su forma dominante, la economía es para Weber una "economía de las probabilidades de poderes de disposición sobre cosas o personas, establecidas o garantizadas por un orden (tradicional o estatuido)" (1922: 51). ${ }^{17}$ Aun a riesgo de resultar reiterativo, diremos que esta "economía de las probabilidades de poderes de disposición" no es otra cosa que una economía de la apropiación o de las probabilidades apropiadas. En este sentido es redundante y con ello impreciso hablar de una economía de la apropiación de poderes de disposición, como hace Weber en ciertos pasajes. Es importante recordar, como señalábamos al comienzo, que el orden económico se constituye a partir de un modo de apropiación, pero también a partir de un modo de distribución, que en la economía de cambio corresponde a las relaciones de mercado. Por ejemplo, ello queda evidenciado cuando hace referencia a las fluctuaciones económicas del proceso de trabajo: "Las posibilidades económicas en cuanto a la disposición del proceso de trabajo son distintas según el modo de distribución de las prestaciones entre economías separadas y según el modo como se apropian las diversas probabilidades económicas, es decir, según la organización de la propiedad (1923: 11)”. Según Weber, es la propiedad la que define la apropiación. Como ya señalamos al comienzo del artículo, en la única definición que ofrece el autor, entiende el concepto de apropiación como “ordenamiento y forma de la propiedad” (1923: 15). Así también, el hecho sociológico de la propiedad privada equivale para Weber a la apropiación de los poderes de disposición de los medios de producción, sujetos al mercado u otros (1922: 70-71). En otra parte señala que una economía con "propiedad" es una economía por apropiación por las economías singulares de los medios de producción (1922: 70-71). Dijimos también que "ser apropiado", en los términos de Weber, es ser objeto del ordenamiento de la propiedad (1923: 15).

16 Weber señala: "Constituye el hecho sociológico más elemental que la forma en que se halla distribuido el poder de posesión sobre bienes en el seno de una multiplicidad de hombres que se encuentran y compiten en el mercado con finalidades de cambio crea por sí misma probabilidades específicas de existencia.

17 En méritos de sencillez, Weber propone llamar a las "probabilidades de poderes de disposición sobre cosas o personas" como "probabilidades" económicas o simplemente "probabilidades", cuando ella no da lugar a equívocos (1922: 51). 
Es necesario señalar que para el sociólogo alemán son tres los "objetos" que pueden ser apropiados en la economía: las oportunidades del trabajo, esto es, los puestos de trabajo y las probabilidades de obtener un ingreso que a ellos se enlazan; los medios materiales de producción; los puestos directivos, es decir, los cargos de empresarios (1923: 15)..$^{18}$

Respecto al primer punto -y en relación con la cita 18 a pie de página-, es importante señalar que para Weber el trabajo se entiende como "apropiación de las oportunidades de trabajo" (1922: 98-100), y que a su vez se pueden identificar cuatro probabilidades de trabajo radicalmente opuestas entre sí: 1) La apropiación monopolista por los trabajadores mismos de las oportunidades de trabajo ("trabajo gremial libre"); 2) la apropiación de las oportunidades

18 Respecto a dichos objetos de apropiación, Weber detalla: "1. En la apropiación de los puestos de trabajo hallamos los siguientes extremos posibles: ausencia de toda apropiación de los puestos de trabajo: el individuo vende su mano de obra libremente, existiendo así un mercado libre de trabajo; puede existir también apropiación de la persona del obrero a través del puesto de trabajo, cuando se convierte en obrero servil o esclavo, propiedad, como objeto, del propietario del puesto de trabajo (...) Finalmente, la apropiación de los puestos de trabajo puede llevarse a cabo por los obreros, bien sea los obreros aislados o (como es más común) por una asociación (asociación reguladora de trabajadores, sindicato) (...) 2. La apropiación de los medios materiales de producción puede corresponder: a) A los trabajadores, tanto individualmente como en grupo. La apropiación individual produce diferentes efectos, según que la utilización de esos medios de producción sea de tipo consuntivo, para satisfacer la propia necesidad o (caso típico del pequeño capitalismo) con carácter lucrativo para el mercado (...) b) La apropiación puede beneficiar también a un propietario que no se identifica con el obrero mismo; tenemos entonces una separación del obrero y de los medios de producción. También en este caso se advierten diferencias según el género de utilización de dichos medios por parte de su propietario. 3. (...) puede darse también la apropiación de los cargos directivos. Desarróllase esta forma paralelamente a la separación que ocurre entre el obrero y los medios de producción, cuya posesión, siquiera sea en forma de préstamo, crea, por el contrario, la función del empresario. También puede ocurrir la apropiación de los obreros (esclavitud) (...). En todo caso, la consecuencia de la apropiación de los puestos directivos por los propietarios es la siguiente: separación de la economía consuntiva y la lucrativa; es ésta una característica de la constitución económica moderna, e incluso resulta impuesta por la ley. Es esencial y decisiva en el negocio su orientación por el principio de rentabilidad. Ahora bien, la coexistencia de la apropiación de los medios de producción y el funcionamiento del negocio, tiene como consecuencia que en la génesis de éste se hagan sentir junto a los intereses patrimoniales personales, otros de carácter irracional (en relación con los intereses del negocio). Ocurre esto sobre todo cuando tiene lugar la separación entre empresarios y propietarios, porque entonces los medios de producción apropiados pueden ser objeto de especulación privada, o también objeto de una política especulativa bancaria o de trust, de manera que también en este caso se hacen valer influencias de tipo irracional, aunque éstas sean de naturaleza adquisitiva y especulativa (1923: 15). 
de trabajo por el propietario de los trabajadores ("trabajo servil"); 3) la ausencia de toda apropiación (trabajo formalmente libre, que es trabajo en méritos de un contrato libre por ambas partes); y por último, 4) la apropiación de las oportunidades de trabajo puede corresponder a una asociación de trabajadores sin que exista apropiación plena o libre, por parte de los trabajadores individuales (1922: 98-100). El trabajo formalmente libre es el único que en apariencia estaría exento de apropiación, aunque con ciertos reparos que ya mencionamos (1922: p. 6).

Por último, parece ser un guiño fenomenal al marxismo el hecho de que en el único momento en que Weber recurre explícitamente a la lógica apropiaciónexpropiación es para intentar explicar la relación de unidad y oposición entre trabajadores y propietarios. Ello aun asumiendo que para él, como señala Giddens, el proceso de "separación" del trabajador de su medio de producción es solamente un ejemplo de un proceso de racionalización de la conducta que se relaciona en todas las esferas de la sociedad moderna (1972: 56). Nuestro autor alude a la relación apropiación-expropiación principalmente para señalar dos aspectos: $a$ ) que la apropiación por los trabajadores de la utilización lucrativa de los productos del trabajo favorece siempre, cuando las demás circunstancias son propicias, la expropiación, más o menos completa, de la dirección al propietario (1922: 98100); y siguiendo la visión marxiana, $b$ ) que la apropiación de los medios materiales de producción por parte de los propietarios o una asociación de los mismos, sólo puede significar aquí la expropiación de los trabajadores de los medios de trabajo y no sólo como individuos sino como totalidad (1922: 108). ${ }^{19}$ En diálogo con las lógicas dialécticas, Weber señala que las dos formas de apropiación formalmente opuestas, la de los puestos de trabajo por los trabajadores y de los trabajadores por un propietario, tienen en la práctica consecuencias muy parecidas, y ello en primera instancia porque las dos se encuentran formalmente unidas entre sí (1922: 101). ${ }^{20}$

19 Igualmente es necesario aclarar que para Weber, a diferencia de Marx, la apropiación de los medios materiales de producción puede ser hecha por el trabajador (individualmente o por una asociación de los mismos), por el propietario, pero también por una asociación de terceros de carácter regulador (1922: 108). En este último caso está haciendo principalmente referencia al accionar al Estado.

20 Weber señala que dicha oposición se concreta “(...) cuando la apropiación de los trabajadores por un señor coincide con las probabilidades lucrativas por una asociación cerrada (...)” (1922: 101). Y posteriormente añade que “(...) aun donde no se da este caso, la apropiación de los trabajadores por un propietario significa de hecho que éste queda entregado forzosamente a la utilización de mano de obra que no ha obtenido por selección libre -como ocurre en la fábrica moderna- sino que ha de aceptar sin posibilidad alguna de elección" (1922: 101). 


\section{A MODO DE CONCLUSIÓN}

Como conclusión presentamos tres hipótesis de trabajo que expresan en buena medida lo que a nuestro entender es el "hallazgo" principal de la investigación conceptual contenida en el artículo. Más que sintetizar los contenidos ya presentados nos ocuparemos en este apartado de señalar algunos aspectos críticos que esperamos puedan orientar futuros trabajos sobre la obra de Weber. Veamos los supuestos:

1) Más allá de sus definiciones explícitas, la apropiación aparece en Weber como un proceso que involucra a las diferentes dimensiones o esferas de lo social y su concepto expresa en cierto punto la tensión irreductible de cierta noción de adquisición y de posesión o poder de disposición, que representarían respectivamente el momento instituyente e instituido de la apropiación, o de sus fuerzas instituidas e instituyentes.

2) El autor excluye la idea de adquisición del concepto de apropiación a favor de cierta idea de posesión o poder de disposición (muchas veces implícita) determinando un dominio total de la segunda sobre la primera, esto es, del momento instituido del proceso ("lo ya-apropiado") sobre el momento instituyente (el de la conquista), hasta prácticamente equiparar el concepto de apropiación con el de posesión o poder de disposición. Ello también quedaría ejemplificado en el uso de la noción de apropiación como probabilidad apropiada, o lo que es lo mismo, como "derecho" y "propiedad".

3) El uso en la práctica de la idea de apropiación como posesión o probabilidad apropiada determina el carácter conservador e institucionalista del concepto y condiciona en dichos términos su teoría de la acción social. El concepto de apropiación de Weber comprende de esta forma una visión materialista, socioeconómica y sociojurídica de la posesión y el poder de disposición, para explicar los procesos sociales y la dinámica de las relaciones de poder.

Repasemos ahora algunos de los razonamientos principales que nos llevaron a postular dichas suposiciones. Teniendo en cuenta sus apariciones escritas, la apropiación para Weber es una probabilidad o posibilidad, que se expresaría más o menos literalmente como el "poder contar con el uso y/o la explotación de una cosa o persona por propia voluntad”. En esta definición, así como en el conjunto que compone la concepción explícita de su idea de apropiación, Weber casi no menciona ni conceptualiza la idea o instancia de la adquisición, ni tampoco establece una relación con ella, siendo que es el concepto de referencia, al menos en su pensamiento económico del momento apropiador. Lejos de resultar baladí, esta constatación nos permitió formular algunas preguntas: Si no es el 
ejercicio o la instancia de la adquisición, ¿qué es lo que distinguiría a la idea de apropiación de la de propiedad? y por lo tanto ¿qué validaría su uso? Pensamos que Weber podría argumentar aquí que la apropiación es propiedad (como probabilidad hereditariamente apropiada) pero también es derecho (probabilidad apropiada), y ello permite establecer un contrapunto y una distinción situacional y temporal vital para la comprensión de la dinámica del poder y de la sociedad. Y podría tener razón. Se nos vino entonces a la mente una segunda idea, que por cierto es más embarazosa: si no es a partir de la incorporación de la instancia de la adquisición en el concepto de apropiación ¿cómo explicaría Weber el paso o la transición de los "intereses de apropiación" (que presupone explícitamente en los actores sociales), a la apropiación como propiedad y/o como derecho, o bien "como forma de organización de la propiedad”? ¿Cómo es posible explicar el proceso de apropiación como el paso de lo apenas pensado a lo yaconsumado? Una última pregunta complica aún más la cuestión: ¿cómo es que hace Weber para activar el movimiento de la apropiación a la expropiación o viceversa sin el momento de la adquisición o de la conquista?

Una de las lecturas peligrosamente equívocas que dicha ausencia podría sugerir es que son los actuales poseedores de derechos y de propiedad, esto es, de poder de disposición, los únicos adquisidores potenciales de objetos y personas por propia voluntad, estableciendo una relación de apropiación a partir del movimiento posesión-posesión, o lo que es lo mismo, de probabilidad apropiadaprobabilidad apropiada. Dejemos hablar a Weber:

“QQué es lo que significa la frase "poder del capital”? Que los poseedores del poder de disposición sobre los medios lucrativos y probabilidades económicas -que pueden ser empleados como bienes de capital en una explotación lucrativa-, en virtud de este poder de disposición y en virtud de la orientación de la gestión económica por los principios del cálculo lucrativo capitalista, logran una específica situación de poder frente a los otros" (1922: 72).

\section{BIBLIOGRAFÍA}

Bendix, Reinhard, Max Weber, Buenos Aires, Amorrortu, 1979.

De Feo, Nicola M., Weber y Lukàcs, Barcelona, A. Redondo, 1972.

Gerts, H. H., C. Wright Mills (eds.), From Max Weber: Essays in Sociology, New York, Oxford University Press, 1946.

Giddens, Antony, Política y sociología en Max Weber, Madrid, Alianza, 1976 (1972). 
Gil, Martha Cecilia, Max Weber, México, Edicol, 1978.

Massot, Vicente Gonzalo, Max Weber y su sombra: la polémica sobre la religión y el capitalismo, Buenos Aires, Forum, 1986.

Mommsen, Wolfgang, Max Weber, sociedad, politica e historia, Buenos Aires, Alfa, 1981 (1974).

Moreno Blauchemin, Ernesto, Max Weber: algunos aportes y desafios, Santiago de Chile, Atenea, 1988.

Nisbet, Robert, La formación del pensamiento sociológico. Tomo I, Buenos Aires, Amorrortu, 2003 (1966).

Poggi, Gianfranco, "Max Weber's Conceptual Portrait of Feudalism", en Hamilton, Peter (ed.), Max Weber I. Critical Assessment, Routledge, 1991 (1988), pp. 79-93.

Robert, Antonio and Ronald Glassman (eds.), A Weber-Marx Dialogue, Kansas, University Press of Kansas, 1985.

Swedberg, Richard (ed.), Max Weber. Essays in Economic Sociology, Princeton University Press, 1999.

Weber, Max, La ética protestante y el espiritu del capitalismo, Madrid, Revista de Derecho Privado, 1955 (1903).

, Economía y Sociedad. Esbozo de sociología comprensiva, Ed. FCE, México, 2008 (1922). , Historia económica general, Ed. FCE, México, 1956 (1923). , El político y el cientifico, Ed. Alianza, Madrid, 1967 (1959). 